\title{
ANALISA FAKTOR-FAKTOR YANG MEMPENGARUHI KEPUASAN DEALER TERHADAP LOYALITAS PARA DEALER PT. DWI PUTERA JAYA
}

\author{
Santoni \\ Program Studi Magister Manajemen Universitas Tarumanagara \\ santoni.kwok@gmail.com \\ Mukti Rahardjo \\ Program Studi Magister Manajemen Universitas Tarumanagara
}

\begin{abstract}
The purpose of this study is to find out 1) whether there is an effect of product quality on loyalty 2) whether there is an effect of price on loyalty 3 ) whether there is a cashback effect on loyalty 4) is there an effect of ontime payment bonus on loyalty. The population in this study were dealers of PT. Dwi Putera Jaya. The sample used in this study was 40 respondents. The sampling technique used was nonprobability sample with purposive sampling method. Overall the results of this study are 1) Product quality has a significant effect on loyalty, 2) Price has a significant effect on loyalty, 3) Cashback has a significant effect on loyalty, 4) Bonus Ontime Payment has a significant effect on loyalty.
\end{abstract}

Keywords : Product Quality, Price, Cashback, Bonus Ontime Payment, Loyalty.

Abstrak : Tujuan penelitian ini adalah untuk mengetahui 1) apakah terdapat pengaruh kualitas produk terhadap loyalitas 2) apakah terdapat pengaruh harga terhadap loyalitas 3) apakah terdapat pengaruh cashback terhadap loyalitas 4) apakah terdapat pengaruh bonus ontime payment terhadap loyalitas. Populasi dalam penelitian ini adalah Dealer-dealer PT. Dwi Putera Jaya. Sampel yang digunakan pada penelitian ini yaitu 40 responden. Teknik pengambilan sampel yang digunakan yaitu nonprobability sample dengan metode pengambilan sampel purposive sampling. Secara keseluruhan hasil dari penelitian ini yaitu 1) Kualitas produk berpengaruh signifikan terhadap loyalitas, 2) Harga berpengaruh signifikan terhadap loyalitas, 3) Cashback berpengaruh signifikan terhadap loyalitas, 4) Bonus Ontime Payment berpengaruh signifikan terhadap loyalitas.

Kata Kunci : Kualitas Produk, Harga, Cashback, Bonus Ontime Payment, Loyalitas.

\section{Latar Belakang}

Di Era globalisasi sekarang ini, persaingan usaha bisnis helm sangat besar dengan tumbuhnya industri-industri kecil di Indonesia. Jumlah penduduk yang semakin besar dan terus bertambahnya jumlah pendapatan juga meningkatkan daya beli masyarakat. Meningkatnya kesejahteraan dan perubahan gaya hidup masyarakat memberikan dampak yang signifikan bagi industri helm dimana masyarakat mulai mencari produk yang mengutamakan keselamatan dan juga sesuai dengan gaya hidup masa kini.

Seiring jalannya waktu, dunia usaha sedang bergerak ke suatu pasar dunia yang mencakup daerah-daerah yang dulu tidak terjangkau menjadi terjangkau. Pergerakan tersebut terjadi karena adanya perubahan-perubahan dalam lingkungan usaha yang tidak terlepas dari pekembangan teknologi informasi dan digitalisasi yang terjadi saat ini. Akibatnya, perusahaanperusahaan dalam suatu industri harus melakukan perubahan-perubahan melalui strategi yang inovatif dan kreatif dalam kegiatan operasionalnya sehingga dapat mengikuti arah pergerakan tersebut dan dapat bersaing dengan baik dalam pasar domestik.

Dalam suatu industri, khususnya industri distributor dan suplai helm kendaraan bermotor, dari waktu ke waktu jumlah pemainnya makin bertambah dengan tumbuhnya 
industri-industri kecil sehingga persaingan di dalamnya semakin ketat. PT.Dwi Putera Jaya (DPJ) adalah distributor helm berbagai merk produksi PT.Tarakusuma Indah yang berada di Cikarang. PT. Dwi Putera Jaya menjual helm dengan merk HIU, BMC, MDS, KYT, INK dan AGV, Pada saat ini terdapat beberapa merk helm yang menjadi pesaing PT.Dwi Putera Jaya antara lain NHK, GM, JPX dan lain-lain. Berdasarkan data dari pihak perusahaan, sejak kegiatan operasinya di Propinsi Riau, PT. DPJ berhasil meraih pangsa pasar yang ckup dominan dalam industri distributor dan suplai helm kendaraan bermotor. Ini merupakan hasil yang baik dan harus terus ditingkatkan agar PT. DPJ mampu menjadi pemimpin pasar dalam industri ini.

PT. DPJ merasa perlu untuk merancang strategi pemasaran baru yang sesuai dengan kondisi pasar saat ini agar mampu bersaing secara kompetitif dan dapat menjadi pemimpin dalam industri ini, sesuai dengan visi perusahaan. Oleh karena itu, studi ini akan melihat bagaimana cara agar PT. DPJ dapat menjalankan usahanya dengan menggunakan strategistrategi pemasaran yang baru, yang lebih efektif untuk melaksanakan visinya sehingga mampu bersaing secara kompetitif dalam pasar domestik terutama di daerah Propinsi Riau yang mencakup 10 Kabupaten dan 2 Kota antara lain Kabupaten Bengkalis, Kabupaten Indragiri Hulu, Kabupaten Indragiri Hilir, Kabupaten Kampar, Kabupaten Kuantan Singingi, Kabupaten Pelalawan, Kabupaten Rokan Hilir, Kabupaten Rokan Hulu, Kabupaten Siak, Kabupaten Kepulauan Meranti, Kota Dumai dan Kota Pekanbaru.

PT. DPJ juga memberikan berbagai macam promosi bagi para dealernya seperti harga yang bersaing, kualitas produk yang baik, program cashback dan pemberian bonus ontime payment 30 hari sehingga dapat meningkatkan penjualan dan kontiniutas pembelian dari para dealer. Salah satu yang mencirikan suatu bisnis dapat dikatakan sukses yaitu bisnis yang dapat menjaga loyalitas pelanggannya. Dengan adanya pelanggan sebuah bisnis akan terus berkembang dan memiliki nilai lebih (Kotler, 2012).

Secara umum, kepuasan adalah hasil dari kinerja suatu produk yang membuat perasaan seseorang menjadi senang atau tidak kecewa dan sesuai dengan yang diharapkan (Kotler, 2012). Oleh karena itu, sebagai leader dalam bisnis helm saat ini, PT. DPJ tidak boleh mengesampingkan kepuasan para dealernya, karena kepuasan para dealer adalah salah satu kunci keberhasilan PT. DPJ sampai saat ini.

\section{Kajian Teori}

Menurut Irawan (2009) Pelanggan puas kalau setelah membeli dan menggunakan produk tersebut, ternyata kualitas produknya baik. Kualitas produk ini adalah dimensi yang global dan paling tidak ada 6 elemen dari kualitas produk, yaiut performance, durability, feature, reliability, consistency, dan design.

Menurut Irawan (2009) Untuk pelanggan yang sensitive, biasanya harga murah adalah sumber kepuasan yang penting karena mereka akan mendapatkan value for money yang tinggi. Komponen harga ini relatif tidak penting bagi mereka yang tidak sensitif terhadap harga.

Menurut Kotler (2012) Untuk pelanggan yang sensitif, biasanya harga yang murah adalah sumber kepuasan yang penting karena mereka akan mendapatkan value for money yang tinggi. Namun bagi pelanggan yang tidak sensitif terhadap harga, akan melihat hasil jasa yang disampaikan perusahan tersebut sesuai dengan harga yang mereka bayar.

Menurut Tjiptono (2007) Program promosi loyalitas banyak diterapkan untuk menjalani relasi antara perusahaan dengan pelanggan. Biasanya program ini memberikan semacam penghargaaan (rewards) khusus, seperti bonus, diskon, voucher, dan hadiah yang dikaitkan dengan frekuensi pembelian atau pemakaian produk dan jasa perusahaan kepada pelanggan rutin agar tetap loyal pada produk dan jasa dari perusahaan.

Menurut Dharmamesta (2000) Loyalitas merupakan respon perilaku/pembelian yang bersifat bias dan terungkap secara terus-menerus oleh pengambil keputusan dengan memperhatikan satu atau lebih merek alternatif dari sejumlah nmerek sejenis dan merupakan 
fungsi proses psikologis. Namun perlu ditekankan bahwa hal tersebut berbeda dengan perilaku beli ulang, loyalitas pelanggan menyertakan aspek perasaan didalamnya.

Menurut Griffin (2005) terdapat empat jenis loyalitas, yaitu: No loyalty, Inertia loyalty, Latent loyalty, dan Premium loyalty. Keempat itu muncul ketika ikatan emosional yang tinggi dan rendah berklasifikasi silang dengan pengulangan dalam pola konsumsi yang tinggi dan rendah.

Menurut Griffin (2006), pelanggan yang loyal adalah mereka yang sangat puas dengan produk atau jasa tertentu sehingga mempunyai antusiasme untuk memperkenalkannya kepada siapapun yang mereka kenal.

Kerangka Pemikiran dalam penelitian ini seperti yang digambarkan dibawah ini:

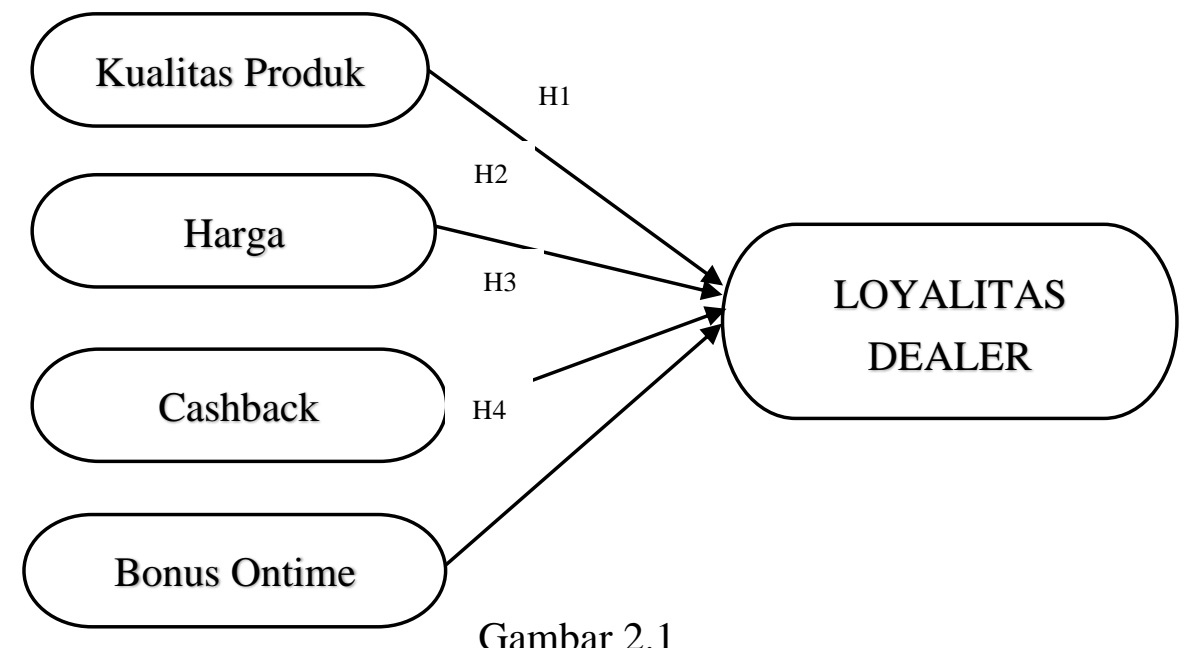

Gambar 2.1

Kerangka Pemikiran

Hipotesis dari model yang dibangun di atas adalah sebagai berikut:

$\mathrm{H}_{1}$ : Terdapat pengaruh Kualitas Produk terhadap Loyalitas.

$\mathrm{H}_{2}$ : Terdapat pengaruh Harga terhadap Loyalitas.

$\mathrm{H}_{3}$ : Terdapat pengaruh Cashback terhadap Loyalitas.

$\mathrm{H}_{4}$ : Terdapat pengaruh Bonus Ontime Payment terhadap Loyalitas.

\section{Metedologi}

Dalam penelitian ini, peneliti menggunakan metode penelitian deskriptif. Penelitian deskriptif dapat membantu peneliti untuk memahami karakteristik suatu kelompok dalam situasi tertentu, berpikir secara sistematis tentang sebuah aspek dalam situasi tertentu, menawarkan ide untuk masalah dan penelitian dimasa yang akan datang, membantu membuat keputusan yang sederhana (Sekaran \& Bougie, 2013). Metode deskriptif merupakan metode yang digunakan untuk menggambarkan atau menganalisis suatu hasil penelitian tetapi tidak digunakan untuk membuat kesimpulan yang lebih luas (Sugiyono, 2005).

Pada penelitian ini, populasi yang diambil pada konsumen PT. Dwi Putera Jaya, dengan sampel sebesar 40, maka itu kuesioner diberi judul: "pengaruh kualitas produk, harga, cashback dan bonus ontime payment terhadap loyalitas pada konsumen PT. Dwi Putera Jaya".

Teknik pemilihan sampel yang digunakan dalam penelitian ini adalah teknik tak acak purposive. Teknik ini digunakan atas dasar kemudahan unsur populasi untuk dijangkau. Untuk itu, unsur populasi yang lebih mudah dapat diperoleh datanya untuk itu unsur itulah yang dapat dijadikan sampel.

Jenis data yang dapat digunakan dalam penelitian ini adalah data primer. Data primer adalah seluruh data yang telah dikumpulkan sendiri oleh peneliti agar dapat menjawab suatu permasalahan penelitiannya. 
Skala Likert dinyatakan sebagai skala nominal karena alternatif tanggapannya bersifat kategorik yang dinyatakan dalam lima kategori, yaitu (1) sangat tidak setuju, (2) tidak setuju, (3) netral, (4) setuju dan (5) sangat setuju.

\section{Hasil Uji Statistik}

Pengujian validitas data dalam penelitian ini diukur dengan menggunakan nilai Corrected Item-Total Correlation. Nilai Corrected Item-Total Correlation pada masingmasing indikator harus dapat lebih besar dari 0,05 dan jika nilai Corrected Item-Total Correlation faktor dibawah dari 0,05 maka indikator tersebut dapat dihapuskan. Pada 5 variabel yang digunakan dalam penelitian ini memiliki nilai sebesar 0,05. Sehingga dapat disimpulkan bahwa semua indikator yang digunakan dalam penelitian ini telah memenuhi syarat.

Pengujian Reliabilitas data dalam Penelitian ini menggunakan cronbach's alpha untuk dapat menguji reliabilitas. Suatu data dapat dinyatakan reliabel jika hasil dari nilai cronbach's alpha > 0,6. Berikut ini merupakan hasil dari nilai cronbach's alpha, Cronbach's alpha Kualitas produk mempunyai nilai 0,752, Harga mempunyai nilai 0,733, Cashback mempunyai nilai sebesar 0,770, Bonus Ontime Payment mempunyai nilai sebesar 0,880 dan Loyalitas mempunyai nilai sebesar 0,747. Dikarenakan nilai cronbach's alpha pada semua variabel dalam penelitian ini lebih besar dari 0,6 maka semua variabel dikatakan reliabel.

$\mathrm{R}^{2}$ digunakan untuk menilai variasi pengaruh antara variabel independen terhadap variabel dependen (Ghozali, 2014). Apabila nilai R-square diatas 0,75 maka mempunyai pengaruh yang kuat, sedangkan 0,5- 0,74 mempunyai pengaruh yang sedang dan 0,25-0,49 memiliki pengaruh yang lemah. Besarnya pengaruh $\mathrm{X}_{1}, \mathrm{X}_{2}, \mathrm{X}_{3}$ dan $\mathrm{X}_{4}$ terhadap $\mathrm{Y}$ pada penelitian ini adalah sebesar $71,8 \%$, dan juga dapat dikatakan koefisien determinasi $\left(\mathrm{R}^{2}\right)$ mempunyai pengaruh yang kuat. Sedangkan $28,2 \%$ variabel loyalitas dipengaruhi oleh variabel lain yang tidak terdapat pada penelitian ini.

Pengujian Hipotesis yang telah dilakukan dalam penelitian ini untuk dapat menentukan apakah hipotesis-hipotesis yang telah dibuat dalam penelitian ini mempunyai pengaruh yang siginifikan. Pengujian hipotesis penelitian ini dilihat dari nilai t-statistik atau p-values.

Berdasarkan hasil pengolahan, dapat diketahui bahwa product quality berpengaruh positif terhadap loyalitas dealer, di mana product quality memperoleh nilai koefisien regresinya sebesar 0.273 dan memiliki nilai signifikansi sebesar 0.017 . Nilai signifikansi yang lebih kecil dari 0.05 menunjukkan product quality berpengaruh positif terhadap loyalitas dealer. Dengan demikian, $\mathrm{H}_{1}$ tidak ditolak.

Hipotesis kedua penelitian ini menyatakan price berpengaruh positif terhadap loyalitas dealer. Berdasarkan hasil pengolahan diperoleh nilai koefisien regresinya sebesar 0.205 dengan signifikansi sebesar 0,035 nilai signifikansinya lebih kecil dari 0,05. maka dapat disimpulkan bahwa variabel price berpengaruh positif terhadap loyalitas dealer. Dengan demikian $\mathrm{H}_{2}$ tidak ditolak.

Berdasarkan hasil pengolahan, dapat diketahui bahwa cashback berpengaruh positif terhadap loyalitas dealer, di mana cashback memperoleh nilai koefisien regresinya sebesar 0.191 dan memiliki nilai signifikansi sebesar 0.005. Nilai signifikansi yang lebih kecil dari 0.05 menunjukkan cashback berpengaruh positif terhadap loyalitas dealer. Dengan demikian, $\mathrm{H}_{3}$ tidak ditolak.

Berdasarkan hasil pengolahan, dapat diketahui bahwa bonus ontime payment berpengaruh positif terhadap loyalitas dealer, di mana kompensasi memperoleh nilai koefisien regresinya sebesar 0.180 dan memiliki nilai signifikansi sebesar 0.019. Nilai signifikansi yang lebih kecil dari 0.05 menunjukkan bonus ontime payment berpengaruh positif terhadap loyalitas dealer. Dengan demikian, $\mathrm{H}_{4}$ tidak ditolak. 


\section{Diskusi}

Dapat dilihat bahwa nilai signifikansi variabel product quality berpengaruh positif terhadap loyalitas dealer, di mana product quality memperoleh nilai koefisien regresinya sebesar 0.273 dan memiliki nilai signifikansi sebesar 0.017. Nilai signifikansi yang lebih kecil dari 0.05 menunjukkan product quality berpengaruh positif terhadap loyalitas dealer. Dengan demikian, $\mathrm{H}_{1}$ tidak ditolak. Hasil dari penelitian ini mengindikasikan bahwa product quality yang baik dapat meningkatkan loyalitas dealer. Hubungan yang positif menunjukkan pengaruh yang searah antar variabel.

Sesuai penelitian Prawiro, et al (2013), product quality yang baik dapat meningkatkan loyalitas consumen secara positif. Konsumen akan merasa puas jika produk yang diinginkan sesuai dengan keinginannya sehingga akan memunculkan loyalitas konsumen.

Dapat dilihat bahwa price berpengaruh positif terhadap loyalitas dealer. Berdasarkan hasil pengolahan yang ditampilkan pada tabel 4.10 diperoleh nilai koefisien regresinya sebesar 0.205 dengan signifikansi sebesar 0,035 nilai signifikansinya lebih kecil dari 0,05. maka dapat disimpulkan bahwa variabel price berpengaruh positif terhadap loyalitas dealer. Dengan demikian $\mathrm{H}_{2}$ tidak ditolak. Hasil dari penelitian ini mengindikasikan bahwa price mempengaruhi loyalitas dealer karyawan secara signifikan. Hubungan yang positif menunjukkan pengaruh yang searah antar variabel. Dengan price yang diberikan perusahaan sesuai dengan hasil pekerjaan yang diterima, maka semakin besar loyalitas dealer.

Hasil tersebut sesuai dengan penelitian Aditia (2012) yang melakukan penelitian terhadap kepuasan pelanggan di UD. Pandan Wangi. Menurut Prawiro, et al (2013), menunjukkan bahwa faktor harga secara simultan berpengaruh secara signifikan kepuasan pelanggan UD. Pandan Wangi.

Dapat dilihat cashback memperoleh nilai koefisien regresinya sebesar 0.191 dan memiliki nilai signifikansi sebesar 0.005. Nilai signifikansi yang lebih kecil dari 0.05 menunjukkan cashback berpengaruh positif terhadap loyalitas dealer. Dengan demikian, $\mathrm{H}_{3}$ tidak ditolak. Hasil dari penelitian ini mengindikasikan bahwa dengan cashback yang diberikan dapat meningkatkan loyalitas dealer. Hubungan yang positif menunjukkan pengaruh yang searah antar variabel.

Penelitian ini sesuai dengan hasil penelitian Prawiro, et al (2013) yang membuahkan hasil bahwa kepuasan konsumen Waroeng Steak dan Shake di Kota Wisata Batu dipengaruhi oleh cashback.

Dapat dilihat bahwa bonus ontime payment berpengaruh positif terhadap loyalitas dealer, di mana kompensasi memperoleh nilai koefisien regresinya sebesar 0.180 dan memiliki nilai signifikansi sebesar 0.019. Nilai signifikansi yang lebih kecil dari 0.05 menunjukkan bonus ontime payment berpengaruh positif terhadap loyalitas dealer. Dengan demikian, $\mathrm{H}_{4}$ tidak ditolak. Hasil dari penelitian ini mengindikasikan bahwa dengan adanya bonus ontime payment dapat meningkatkan loyalitas dealer. Hubungan yang positif menunjukkan pengaruh yang searah antar variabel.

Hal ini sesuai dengan penelitian Harun (2006) yang menyatakan bahwa bonus ontime payment dapat meningkatkan loyalitas consumen.

\section{Penutup}

Penelitian ini bertujuan untuk mengetahui pengaruh product quality, price, cashback dan bonus ontime payment pada perusahaan PT. Dwi Putera Jaya. Berdasarkan hasil analisis dapat disimpulkan bahwa:

1. Product quality berpengaruh positif terhadap loyalitas dealer. Sesuai penelitian Prawiro, et al (2013), product quality yang baik dapat meningkatkan loyalitas consumen secara positif. Konsumen akan merasa puas jika produk yang diinginkan sesuai dengan keinginannya sehingga akan memunculkan loyalitas konsumen. 
2. Price berpengaruh positif terhadap loyalitas dealer. Hasil tersebut sesuai dengan penelitian Aditia (2012) yang melakukan penelitian terhadap kepuasan pelanggan di UD. Pandan Wangi. Menurut Prawiro, et al (2013), menunjukkan bahwa faktor harga secara simultan berpengaruh secara signifikan kepuasan pelanggan UD. Pandan Wangi.

3. Cashback berpengaruh positif terhadap loyalitas dealer. Penelitian ini sesuai dengan hasil penelitian Prawiro, et al (2013) yang membuahkan hasil bahwa kepuasan konsumen Waroeng Steak dan Shake di Kota Wisata Batu dipengaruhi oleh cashback.

4. Bonus ontime payment berpengaruh positif terhadap loyalitas dealer. Hal ini sesuai dengan penelitian Harun (2006) yang menyatakan bahwa bonus ontime payment dapat meningkatkan loyalitas consumen.

\section{Daftar Rujukan/Pustaka}

Ghozali, I., 2009. Ekonometrika Teori, Konsep dan Aplikasi dengan SPSS 17. Semarang: Badan Penerbit Universitas Diponegoro.

Griffin. J. 1995, Customer Loyalty : How to Earn It and Keep It. Lexington Books, New York, NY.

Philip Kottler. 2000. "Marketing Mangement". Prentice Hall

Sugiyono, 2012. Metode Penelitian Bisnis. Cetakan ke-16. Alfabeta. Bandung.

Tjiptono, F. (1998). "Prinsip-prinsip Total Quality Service". Andi Offset, Yogyakarta. 